\title{
THE DIMENSIONS OF ACADEMIC SCHOLARSHIP: Faculty and Administrator Views
}

\author{
Glenn R. Pellino, Robert T. Blackburn, and Alice L. Boberg
}

Faculty and administrators responded to 32 activity statements related to "scholarship" on a frequency basis and on the characteristicness of the role. Approximately 1,000 faculty members in 24 colleges and universities and 55 administrators from 5 of the schools participated. Factor analysis revealed 6 dimensions of scholarship-professional activity, research (publishing), teaching, service, artistic endeavor, and "engagement with the novel," the last being a new conception, one valued highly by both faculty and administrators in all types of colleges and universities. Significant differences appeared with respect to faculty and administrative views on the importance of research in regional universities.

Spurred especially by the scientific and technological revolution of the 1960 s, a concern with increasing research productivity has generated a prodigious number of research studies on research. By and large, however, these inquiries have been directed to answering one question: What are the correlates of research? In addition, these studies have been limited by an overreliance on a single measure of research productivity, namely, scholarly publications. The questions of how and why faculty go about pursuing their research interests have remained largely uninvestigated. Indeed, genuine ambiguity even exists as to what constitutes academic "scholarship," particularly in those institutions that do not claim to have major research functions, such as community colleges and 4-year teaching institutions.

From a statistical perspective, the distribution of scholarly publications is badly skewed. Nearly $60 \%$ of all those employed full-time in academic positions have never brought to publication a book (written or edited), and over half have published nothing or very little (Ladd and Lipset, 1978). Other studies have shown that $90 \%$ of the research articles in journals are

Glenn R. Pellino, University of Scranton; Robert T. Blackburn, University of Michigan; Alice L. Boberg, University of Calgary.

Research in Higher Education (C) Agathon Press, Inc. Vol. 20, No. 1, 1984 
written by about $10 \%$ of the college and university faculty members (Berelson, 1960; Ladd, 1979).

One might assume that these figures merely approximate the number of faculty interested in research and publication or those rewarded for publication. That is, those who wish to do, do; those who do not wish to, do not. However, this response misses the target. Blackburn, Pellino, Boberg, and O'Connell (1980) found that faculty from every type of institutioncommunity college, liberal arts college, and university - indicate an anxiety about their scholarly role. They desire to give more time to scholarship and to increase their output. In addition, Baldwin and Blackburn (1981) found that interest in increased scholarly productivity persisted throughout the various stages of the academic career.

How, then, is one to interpret this desire on the part of large numbers of faculty to increase the time they devote to scholarship in the light of known rates of publication? Can one assume that everyone in higher education knows and agrees upon what the activities are that constitute scholarship?

This study had two principal goals: (1) to determine the components of what faculty consider to be the essence of their creative ("scholarly") role; and (2) to compare administrator and faculty beliefs on the importance of the various dimensions of scholarship.

\section{RESEARCH DESIGN AND METHODOLOGY}

The study involved the administration and analysis of a survey of faculty in selected colleges and universities for the purpose of identifying their attitudes regarding scholarship. Factor analysis was used to uncover and describe the underlying pattern in this set of multivariate data. No hypotheses concerning either the nature or number of factors (dimensions) present in the data were proposed prior to the running of the factor program. In addition, no hypotheses about the magnitude of factor loadings or the existence of hypothetical constructs were tested. Essentially, factor analysis was used as an exploratory technique rather than as a confirmatory one.

The factor analysis was utilized to provide heuristic dimensions of faculty attitudes toward scholarship. Indices representing the dimensions derived from the factor analysis were constructed for use in further analysis to determine the degree to which faculty and administrators' attitudes toward scholarship vary. Twenty-four colleges and universities ( 8 community colleges, 8 liberal arts colleges, and 8 universities) were purposefully selected for inclusion in the faculty development study on the basis of the maturity and distinctiveness of their faculty development programs.

Questionnaires were mailed to 2,000 randomly selected faculty members. 
Respondents were asked to indicate the amount of time they spent engaged in activities which they felt were scholarly, and whether or not they were involved in systematic inquiry leading to the publication of books or articles in professional journals. Faculty also responded to 32 activity statements (e.g., reviewed an article for a journal; prepared a new set of lectures) along two 5-point scales, one on how frequently they engaged in the activity and the other on how central the activity was to their conception of their scholarship. (See footnote for Table 10 for questionnaire format.) Usable returns numbered $1,063(50 \%)$. Sets of administrators $(N=8$ to $15 /$ institution) at 5 of the 24 colleges and universities later responded to a comparable instrument. (Since the institutions selected the administrators, the number of subjects is not exactly known. However, the number of returns is almost exactly equal to the number of instruments requested. An estimate of an $80 \%$ response rate is conservative.)

A factor analysis using the FACTOR subprogram in SPSS was conducted on the faculty's rating of their conception of scholarship. A principal-components solution was performed to determine the number of original factors and to estimate the initial communalities. The original factors were then rotated to oblique factors using the default value for delta $(\delta)$. Oblique rotation was utilized, since the factors extracted through a varimax solution were intercorrelated. Mean factor scores were computed using listwise deletion for missing cases and then arithmetically converted to a standard 5-point scale for comparison purposes.

A test/retest method was employed to judge the reliability of the faculty instrument. Sixty of the instruments were sent to original respondents randomly selected across the institutions. A pairwise $t$-test on each item was performed to detect if respondents had changed their category of agreement/ disagreement rather than their degree of agreement/disagreement. This statistic was chosen over the traditional Pearson product moment correlation because a number of respondents raising their degree of agreement can lead to an artificially smaller $r$. The $t$-tests showed a significant difference in means $(p<.05)$ in 5 out of the 74 items, and of the 5 only 3 were included in the factor analysis. The small number of items was not deemed to endanger the reliability of the instrument, since no more than one of the questionable items appeared in any factor. In addition, calculations of Cronbach alpha coefficients indicated a decrease in the coefficient when the items were deleted in the calculations. In addition, Allison and Stewart (1974) have found faculty to be accurate reporters of their work activities.

When the respondents were checked on the demographic characteristics of sex, age (5-year intervals), and tenure status against $1978 \mathrm{ACE}$ and 1979 NCES data, the fits were always within $3 \%$. The sample has the characteristics of the national population of faculty. 


\section{RESULTS}

As noted earlier, research on faculty scholarship has tended to restrict the definition of scholarship to systematic inquiry leading to the publication of books and of articles in professional journals. In this study, faculty were asked to indicate whether or not they were involved in research of this restricted type: "Are you actively involved in research which you expect to lead to publication? If you are not now, have you been in the past?" Responses by institutional levels are shown in Table 1.

The pattern of responses suggests that outside of the research universities (U-B) large numbers of faculty are not engaged in what is normally called research. Nonactive researchers exceed $40 \%$ at the regional universities, approach $40 \%$ at the more selective liberal arts colleges, are a majority at the less selective liberal arts colleges, and account for fully three-quarters of the faculty at community colleges.

Faculty were also asked the amount of time each week they engaged in scholarly activities: How many hours a week are you engaged in activity you consider to be of a scholarly nature? (This includes research and all other creative professional activities. Please exclude those hours spent in teaching and immediate classroom preparation.) Responses by institutional level are presented in Table 2 . As is readily appatent, the vast majority of faculty (a

TABLE 1. Involvement by Faculty in Research by Institutional Types in Percentages $^{2}$

\begin{tabular}{|c|c|c|c|c|}
\hline & (N) & $\begin{array}{c}\text { Now } \\
\text { Involved }\end{array}$ & $\begin{array}{l}\text { Not Presently } \\
\text { Active But } \\
\text { Active in Past }\end{array}$ & $\begin{array}{c}\text { Not Active } \\
\text { Since } \\
\text { Graduate School }\end{array}$ \\
\hline $\mathrm{cc}$ & $(104)$ & 22.2 & 21.1 & 56.7 \\
\hline LAC-A & $(90)$ & 48.8 & 11.9 & 39.3 \\
\hline LAC-B & (195) & 61.9 & 20.5 & 17.6 \\
\hline $\mathrm{U}-\mathrm{A}$ & $(107)$ & 57.5 & 22.2 & 20.4 \\
\hline $\mathrm{U}-\mathrm{B}$ & (103) & 89.2 & 6.3 & 4.5 \\
\hline
\end{tabular}

\footnotetext{
anstitutional classifications

CC: Comunity/Junior Colleges; Private and Public

LAC: Liberal Arts Colleges; all are private/residential B.A. or B.S. degree.

U: ' Universities; Private and Public

The A and B essentially follow the Carnegie council (1976) classification.

" $\mathrm{B}$ " tends to mean more selective (and "A" less selective) with regard to student ability in the case of the LACs and the Us. In the case of the Us, an "A" most often is a regional university which has few if any doctoral programs; a " $B$ " tends to be a research oriented university.
} 
TABLE 2. Distribution of Time Devoted by Faculty to Scholarly Activity by Institutional Types in Percentages

\begin{tabular}{|c|c|c|c|c|c|c|}
\hline & (N) & None & $\begin{array}{c}1-5 \\
\text { hours }\end{array}$ & $\begin{array}{c}6-10 \\
\text { hours }\end{array}$ & $\begin{array}{l}11-20 \\
\text { hours }\end{array}$ & $\begin{array}{l}>20 \\
\text { hours }\end{array}$ \\
\hline $\mathrm{CC}$ & $(106)$ & 5.0 & 50.0 & 23.7 & 3.1 .2 & 10.1 \\
\hline LAC-A & $(90)$ & 6.0 & 51.8 & 20.5 & 10.8 & 10.8 \\
\hline LAC-B & (193) & 2.6 & 45.2 & 27.5 & 17.6 & 7.0 \\
\hline$U-A$ & $(106)$ & 3.0 & 32.0 & 33.7 & 20.7 & 10.7 \\
\hline$U-B$ & (104) & 1.8 & 15.6 & 25.9 & 25.4 & 31.3 \\
\hline
\end{tabular}

range of $94 \%$ to $98 \%$ ) indicated that they engage in what they consider to be scholarly activity of some kind.

\section{Factor Analysis}

The factor analysis of the 32 activities produced six distinct dimensions. The oblique solution is presented in Table 3 . The six dimensions utilize 29 of the 32 items, 3 being eliminated either because they failed to discriminate between two factors or did not fit conceptually with the factor on which they loaded. Cronbach alpha coefficient values were used as a measure of the reliability.

Factor 1. Scholarship as Professional Activity. The five items defining this factor (Table 4) reflect activities which characterize professional service to the discipline and are generally practiced by recognized scholars in the field. The activities reflect the exercise of responsibility for maintaining standards of quality through critique and review (items 12,15, 16). This concern for quality extends to the area of research funding itself (item 14). Recognition is also given for presentations to one's colleagues and students (item 11).

Factor 2. Scholarship as Research/Publication. This factor reflects the traditional concept of scholarship. The five items defining this factor (Table 5) all contain commitment to knowledge production and dissemination through traditional scholarly channels.

Factor 3. Scholarship as Artistic Endeavor. The content of the three items defining this factor (Table 6) imply an orientation and involvement with the arts. Both the performance and public aspect of artistic creation (item 26) as well as the enhancing of one's talents (items 31 and 32) are captured by this dimension of scholarship.

Factor 4. Scholarship as Engagement with the Novel. The content of the four items that make up this factor (Table 7) was as unexpected as is the title given to it. Consequently, the interpretation is less clear than for the other four factors. Each of the four items can be taken to be a secondary 
TABLE 3. Six Factor Solution: Loadings

\begin{tabular}{|c|c|c|c|c|c|c|}
\hline $\begin{array}{c}\text { Item } \\
\text { Number }\end{array}$ & $\begin{array}{c}1 \\
\text { Profes- } \\
\text { sional } \\
\text { Activity }\end{array}$ & $\begin{array}{c}2 \\
\text { Research/ } \\
\text { Publication }\end{array}$ & $\begin{array}{c}3 \\
\text { Artistic } \\
\text { Endeavor }\end{array}$ & $\begin{array}{c}4 \\
\text { Engagement } \\
\text { with the } \\
\text { Novel }\end{array}$ & $\begin{array}{c}5 \\
\text { Community } \\
\text { Service }\end{array}$ & $\begin{array}{c}6 \\
\text { Pedagogy }\end{array}$ \\
\hline 8 & .23 & .30 & .08 & .23 & .32 & .23 \\
\hline 9 & .45 & .71 & .12 & .28 & .38 & .17 \\
\hline 10 & .39 &.$\overline{21}$ & .23 & .29 & .70 & .26 \\
\hline 11 & .55 & .56 & .10 & .29 &.$\overline{37}$ & .36 \\
\hline 12 &.$\overline{69}$ & .29 & .47 & .14 & .54 & .37 \\
\hline 13 &.$\overline{23}$ & .11 & .30 & .10 & .58 & .31 \\
\hline 14 & .76 & .51 & .29 & .32 &.$\overline{43}$ & .26 \\
\hline 15 & .74 & .72 & .05 & .35 & .30 & .25 \\
\hline 16 & .79 & .65 & .25 & .28 & .36 & .27 \\
\hline 17 &.$\overline{24}$ & .23 & .03 & .36 & .24 & .71 \\
\hline 18 & .46 & .23 & .32 & .22 & .46 &.$\overline{57}$ \\
\hline 19 & .15 & .17 & .03 & .30 & .23 & .73 \\
\hline 20 & .32 & .29 & .19 & .28 & .52 &.$\overline{51}$ \\
\hline 21 & .31 & .18 & .33 & .21 & .38 &.$\overline{64}$ \\
\hline 22 & .11 & .18 & .11 & .26 & .28 &.$\overline{76}$ \\
\hline 23 & .20 & .13 & .20 & .24 & .29 &.$\overline{60}$ \\
\hline 24 & .23 & .37 & .09 & .53 & .28 &.$\overline{55}$ \\
\hline 25 & .47 & .88 & .02 & .42 & .23 &.$\overline{22}$ \\
\hline 26 & .39 &.$\overline{11}$ & .76 & .24 & .32 & .18 \\
\hline 27 & .59 & .71 & .42 & .25 & .31 & .30 \\
\hline 28 & .54 & .75 & .30 & .34 & .28 & .31 \\
\hline 29 & .47 &.$\overline{90}$ & .03 & .42 & .22 & .22 \\
\hline 30 & .49 & .40 & .50 & .23 & .50 & .37 \\
\hline 31 & .40 & .34 & .67 & .22 &.$\overline{36}$ & .30 \\
\hline 32 & .27 & .01 & .68 & .23 & .29 & .15 \\
\hline 33 & .25 & .24 & .29 & .44 & .31 & .56 \\
\hline 34 & .31 & .19 & .33 & .52 & .36 & $\overline{44}$ \\
\hline 35 & .39 & .20 & .41 &.$\overline{28}$ & .27 & .35 \\
\hline 36 & .56 & .29 & .51 & .43 & .31 & .22 \\
\hline 37 & .33 & .41 & .13 & .64 & .17 & .36 \\
\hline 38 & .20 & .29 & .18 & .56 & .31 & .39 \\
\hline 39 & .40 & .37 & .32 & .64 & .56 & .34 \\
\hline Eigenvalue & 10.07 & 2.67 & 2.09 & .88 & .73 & .47 \\
\hline $\begin{array}{l}\text { Percent of } \\
\text { variance }\end{array}$ & 59.5 & 15.8 & 12.4 & 5.2 & 4.3 & 2.8 \\
\hline $\begin{array}{c}\text { Cumulative } \\
\text { percent }\end{array}$ & 59.5 & 75.3 & 87.7 & 92.9 & 97.2 & 100.0 \\
\hline Cronbach & & & & & & \\
\hline alphas & .86 & .89 & .79 & .72 & .63 & .85 \\
\hline
\end{tabular}

Note. Item (questionnaire number) descriptions are in the separate tables for each factor.

or corollary characteristic of one of the other four factors. The acquisition of a new research technique (item 37) could be interpreted as a foundational component of Factor 2 (Scholarship as Research/Publication). Also, the introduction of scholarship in consulting (item 39) could certainly be viewed as a manifestation of Factor 5 (Scholarship as Community Service). (See below.) Supervising students working on creative projects (item 38 ), on the other hand, appears to be an adjunct of Factor 6 (Scholarship as Pedagogy). (See below.) Finally, the development of a new process for dealing with a problem is akin to the creative act present in Factors 1 and 2. What characterizes these activities is the continued emphases on new, integrative, 
TABLE 4. Factor 1-Scholarship as Professional Activity: Items and Factor Loadings

\begin{tabular}{|c|c|c|}
\hline Q⿻肀二3 & Activity & Loading \\
\hline 16 & Served on an editorial board of a journal ......... & .79 \\
\hline 14 & Reviewed proposals for a funding agency .......... & .76 \\
\hline 15 & Reviewed articles for a professional journal. . . . . . & .74 \\
\hline 12 & Served as a member on an accreditation team . . . . . . & .69 \\
\hline 21 & Delivered a colloquiun open to faculty and students . . . . & .55 \\
\hline Percent & of Total Variance & \\
\hline Cronbach & Alpha & \\
\hline
\end{tabular}

TABLE 5. Factor 2-Scholarship as Research/Publication: Items and Factor Loadings

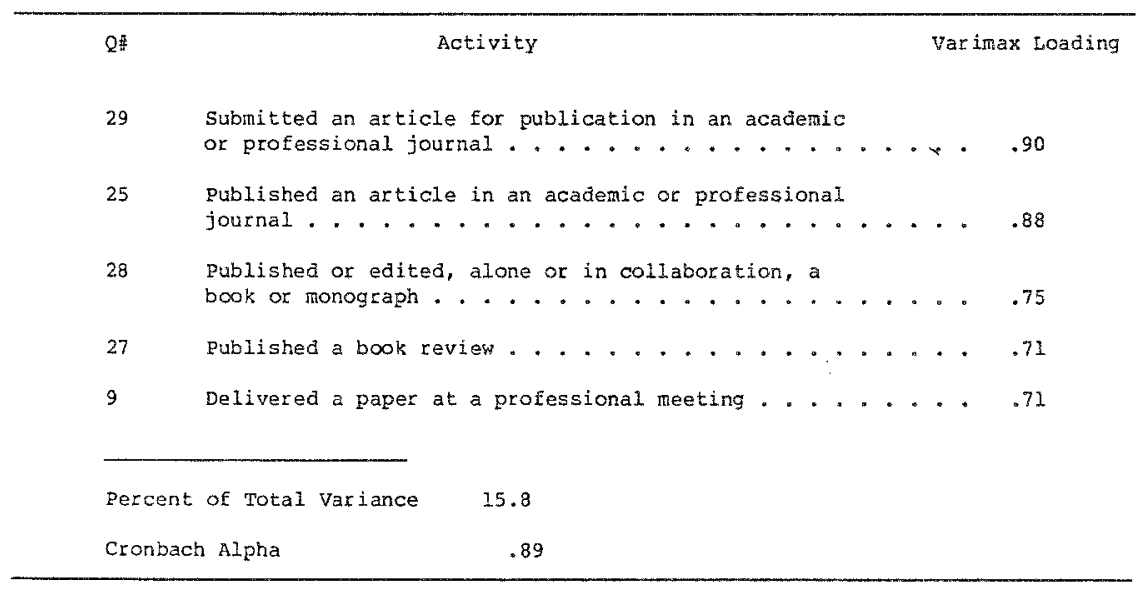

TABLE 6. Factor 3-Scholarship as Artistic Endeavor: Items and Factor Loadings

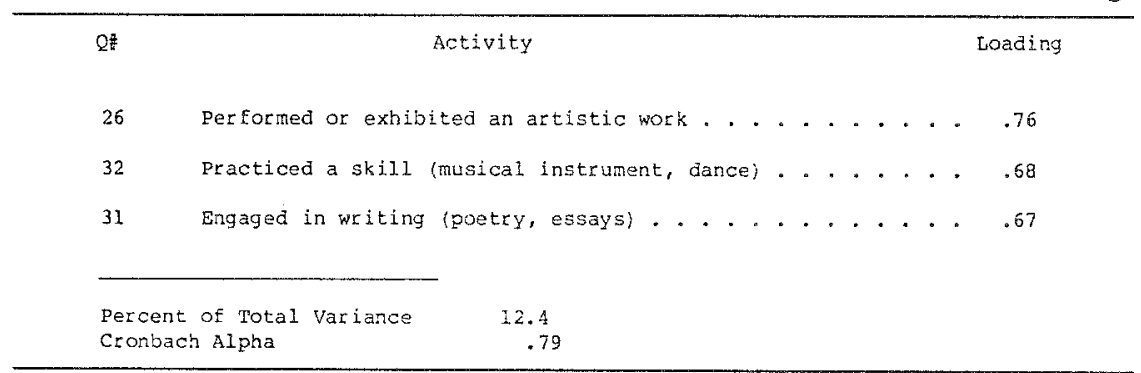

$\mathrm{QH}=$ corresponding question number on instrument. 
T ABLE 7. Factor 4-Scholarship as Engagement with the Novel: Items and Factor Loadings

\begin{tabular}{|c|c|c|c|c|c|}
\hline$Q \#$ & Activity & & & Varima & $x$ Loading \\
\hline 37 & $\begin{array}{l}\text { Engaged in systematic study to gain new knowledge or } \\
\text { acquire a new research technique. } . .+\cdot \cdot \cdot \cdot \cdot \cdot \text {. }\end{array}$ & $\cdot$ & $\cdot$ & $\cdot \cdot$ & .64 \\
\hline 39 & $\begin{array}{l}\text { Introduced some result of your scholarship in a } \\
\text { consultation. . . . . . . . . . . . . . . . . . }\end{array}$ & $\cdot$ & . & $\cdot \cdot$ & .64 \\
\hline 38 & Supervised students working on creative projects. . . & - & - & $\cdot \cdot$ & .56 \\
\hline 34 & Developed a new process for dealing with a problem. . & $\cdot$ & $\cdot$ & - & .52 \\
\hline Percent o & of Total Variance & & & & \\
\hline Cronbach & A.lpha & & & & \\
\hline
\end{tabular}

or creative activity. At the same, this could be an important dimension of scholarship, as independent of the other (more recognizable) five as they are of each other. This observation will be returned to in the discussion section below.

Factor 5. Scholarship as Community Service. The two items that define this factor (Table 8) reflect an involvement in service-related activities external to the college. They portray faculty sharing their expertise in the public sector either through consulting (item 10) or by making presentations to civic or religious organizations (item 13).

Factor 6. Scholarship as Pedagogy. The nine items defining this factor (Table 9) clearly revolve around the instructional process. The preparation of new materials for use in the classroom whether they be a new syllabus (item 22), a set of lectures (item 19), or a novel testing practice (item 21) are important elements of this dimension of faculty scholarship. Also characteristic of this factor are such foundational activities as doing library research

TABLE 8. Factor 5-Scholarship as Community Service: Items and Factor Loadings

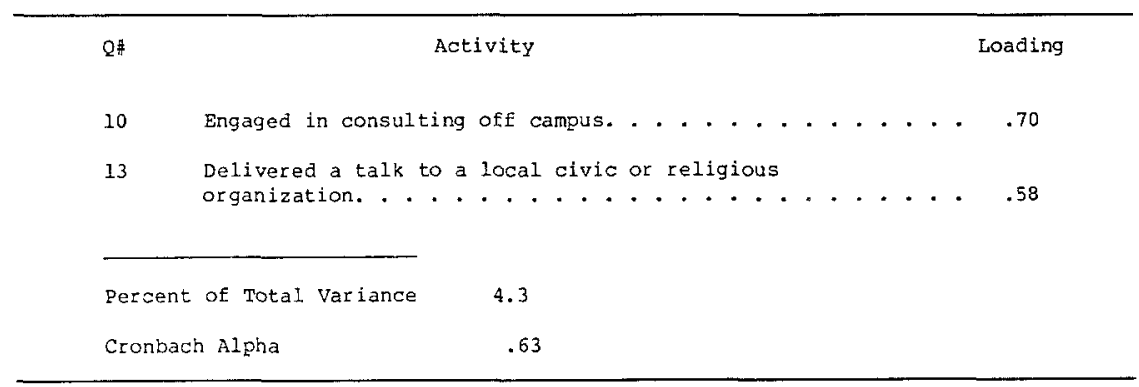


TABLE 9. Factor 6-Scholarship as Pedagogy: Items and Factor Loadings

\begin{tabular}{|c|c|c|}
\hline$Q \notin$ & Activity & Loading \\
\hline 22 & Prepared a new (and extensive) syllabus for a course. . . . & .76 \\
\hline 19 & 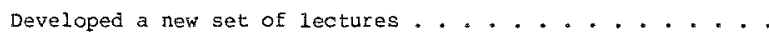 & .73 \\
\hline 17 & Did library research in revising the content of a course. & .71 \\
\hline 21 & 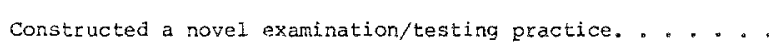 & .54 \\
\hline 23 & 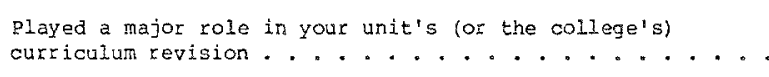 & .60 \\
\hline 18 & 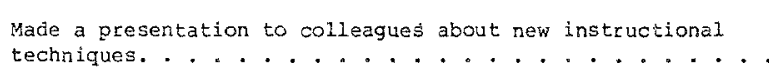 & .57 \\
\hline 33 & 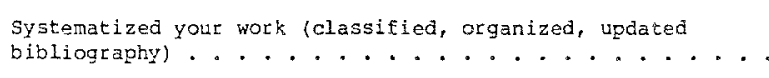 & .56 \\
\hline 24 & 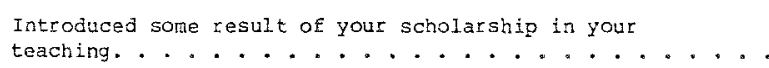 & .55 \\
\hline 20 & Served as a guest lecturer in a colleague's class..... & .51 \\
\hline Percent & of Total Variance & \\
\hline Cronbach & h Alpha & \\
\hline
\end{tabular}

(item 17), systematizing one's own work (item 33) in preparation for teaching, and taking care to introduce the results of one's scholarship in teaching (item 24). Classroom teaching, however, is not the only area in which this particular scholarly effort is found. Involvement in the broader instructional program - by becoming involved in curriculum revision (item 23), by sharing ideas on new instructional techniques (item 18), or by serving as a guest lecturer in a colleague's class - is also a manifestation of this type of scholarship.

Factors Means by Institutional Types. Table 10 displays the means for each factor for the five institutional types, each transcribed to a 5-point scale so comparisons can be made. The differences in the relative importance given to the various dimensions as well as the differences between types of institutions are apparent. "Teaching" receives the highest score in all types of institution except the research-oriented universities where "publishing" (3.36) and "engagement with the novel" (3.26) are more important. It is interesting to note that "engagement with the novel" receives the second highest score across all institutional types.

Administrative/Faculty Comparisons. Table 11 shows the comparison of factor mean scores of faculty and administrators at five institutions. (The instruments used with faculty and administrators were not identical in every 


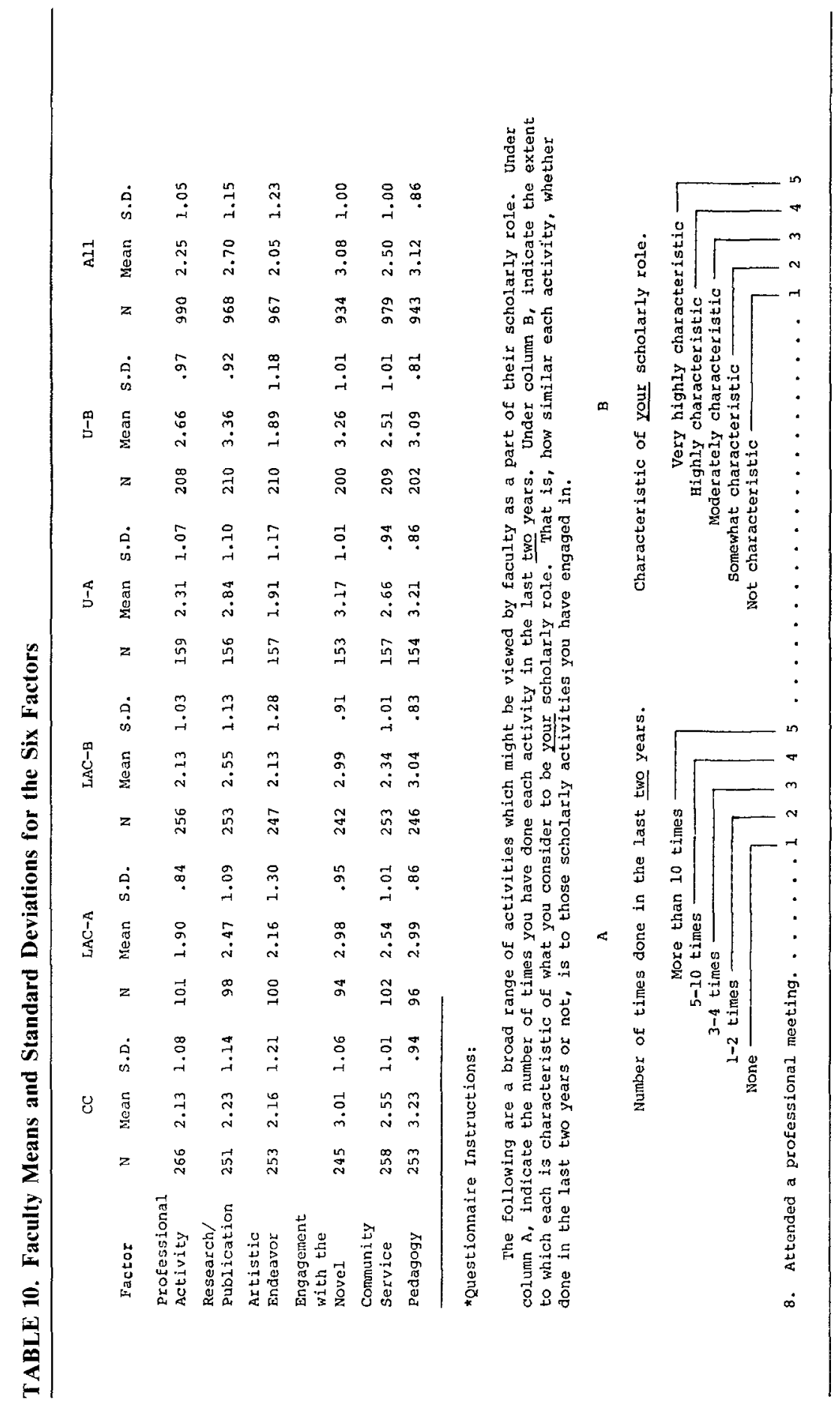




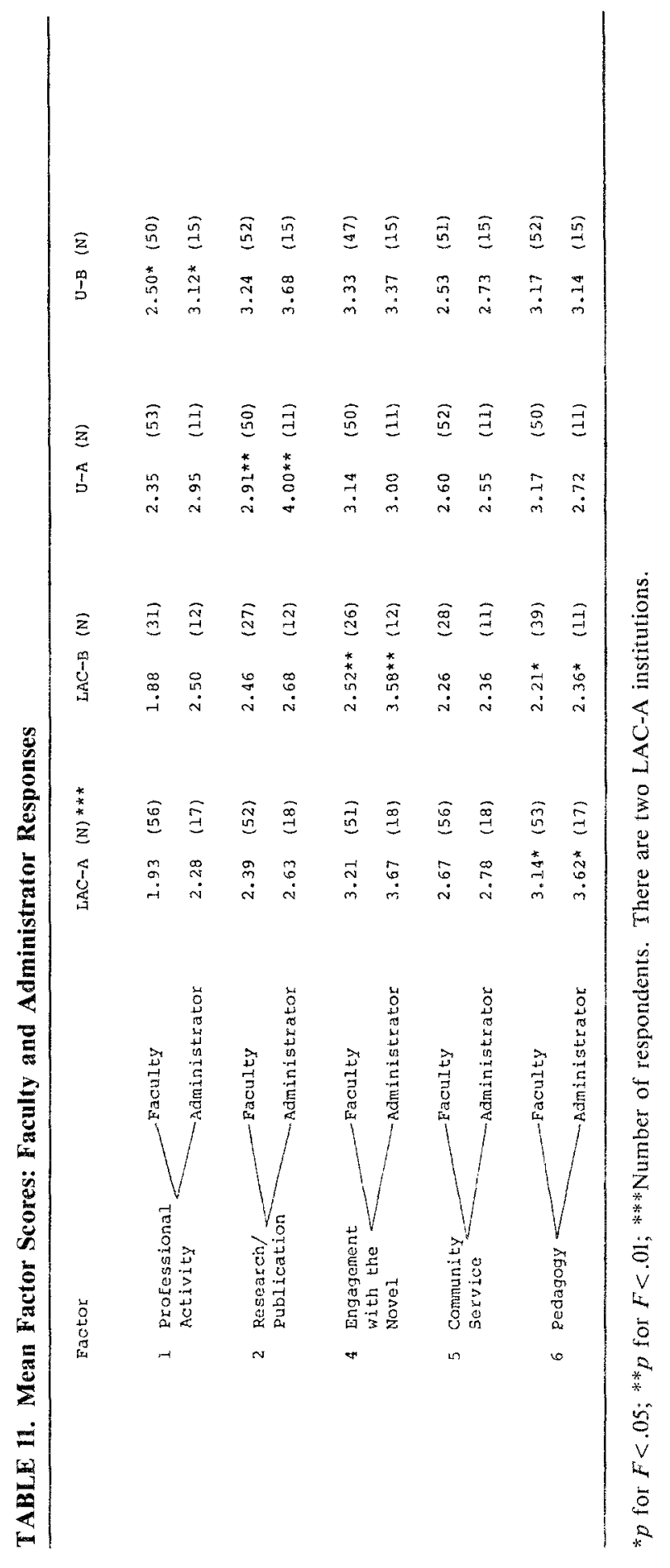


respect, but they did overlap in essential ways. The principal difference was that faculty were able to express the amount of time and importance that they believe artistic expression plays in the scholarly role, while administrators did not have this option, since they took a typical arts and science faculty member as their model. Therefore, it is not possible to provide comparative data for the artistic dimension.) As Table 11 indicates, faculty at liberal arts college do not perceive "professional activity" (Factor 1) to be characteristic of their scholarship. While faculty at the universities judge this factor to be moderately characteristic of scholarship, administrators ranked this factor even higher (significantly so at research-oriented universities).

"Research/publication" (Factor 2) was judged by both faculty and administrators in the liberal arts colleges to be moderately characteristic of faculty scholarship. As one would expect, faculty and administrators at the research universities agree that publishing is the essence of scholarship. At the regional universities (U-A), moreover, a significant difference exists between the two groups on the essentialness of research: administrators have significantly higher expectations $(4.00, p<.01)$ than do faculty $(2.91)$. These expectations are even higher than those of administrators at research universities (U-B), namely, 4.00 versus 3.68 . There is a reasonably high agreement among faculty and administrators on the values of Factor 4 ("engagement with the novel"). On one campus (LAC-B, a more selective liberal arts college) administrators rate this factor significantly higher than faculty do $(3.58$ versus $2.52, p<.01)$.

While there is reasonably high agreement among faculty and administrators at the universities on the value of teaching activities as an important dimension of scholarship, faculty and administrators have significantly different opinions at the liberal arts college. An interesting aspect of these differences is the low value placed upon the pedagogy factor by faculty at selective liberal arts college (2.21), institutions priding themselves as facultied by the teacher/scholar.

\section{DISCUSSION}

The factor solution suggests six dimensions of faculty scholarship. Four of these constructs (Factors 1, 2, 6, and 5) appear to be role specific. That is, they indicate that faculty view as most characteristic of their scholarship activities related to the four most often identified aspects of faculty work, namely, professional activity, research, teaching, and service. The precise extent and way that faculty give meaning to these notions of scholarship, particularly teaching and service, open a new field of investigation. Clearly, faculty who are not productive, using professional activity and publication standards, perceive their work to be in some fashion scholarly. How this 
scholarship vitalizes and contributes to their work needs increased understanding.

From both a theoretical and practical perspective, Factor 4 ("engagement with the novel") is interesting. Both faculty and administrators rate it very high-above traditional research in some institutions and above teaching in others. The general expectation that scholarship can be creative and integrative in whatever its particular exemplification is significant. Since "engagement with the novel's" high value is shared by both faculty and administrators, ways need to be found to assess and recognize this aspect of scholarship. Also from a practical perspective, administrators in institutions that have appreciable discrepancies between their own expectations and faculty expectations need to confront the data. Unproductive conflict can arise in settings where, for example, faculty believe their teaching is their creative effort but administrators value traditional research.

\section{REFERENCES}

Allison, P. D., and Stewart, J. A. Productivity differences among scientists: evidence for accumulative advantage. American Sociological Review, 1974, 39, 596-606.

Baldwin, R. G., and Blackburn, R. T. The academic career as a developmental process: implications for higher education. Journal of Higher Education, 1981, 52, 598-614.

Berelson, B. Graduate Education in the United States. New York: McGraw-Hill, 1960.

Blackburn, R. T., Pellino, G., Boberg, A., and O'Connell, C. Faculty development programs, the improvement of instruction, and faculty goals: an evaluation. In R. Edgerton (Ed.), Current Issues in Higher Education. Washington, D.C.: American Association for Higher Education, 1980, pp. 32-48.

Carnegie Council on Policy Studies in Higher Education. A Classification of Institutions of Higher Education. Berkeley, Calif., 1976.

Ladd, E. C., Jr. The work experience of American College professors: some data and an argument. In R. Edgerton (Ed.), Current Issues in Higher Education. Washington, D.C.: American Association for Higher Education, 1979, pp. 3-12.

Ladd, E. C., Jr., and Lipset, S. M. Technical Report: 1977 Survey of the American Professoriate. Storrs: Social Science Data Center, University of Connecticut, 1978.

Received April 12, 1983 